\title{
Proteomic approaches to the study of renal mitochondria
}

\author{
Zdenek Tumaa , Jitka Kuncovaa, ${ }^{\mathrm{a}, \mathrm{b}}$, Jan Mares ${ }^{\mathrm{a}, \mathrm{c}}$, Martina Grundmanova ${ }^{\mathrm{a}, \mathrm{b}}$, Martin Matejovic ${ }^{\mathrm{a}, \mathrm{c}}$
}

\begin{abstract}
Background and Aims. Dysfunction of kidney mitochondria plays a critical role in the pathogenesis of a number of renal diseases. Proteomics represents an untargeted attempt to reveal the remodeling of mitochondrial proteins during disease. Combination of separation methods and mass spectrometry allows identification and quantitative analysis of mitochondrial proteins including protein complexes. The aim of this review is to summarize the methods and applications of proteomics to renal mitochondria.

Methods. Using keywords "mitochondria", "kidney", "proteomics", scientific databases (PubMed and Web of knowledge) were searched from 2000 to August 2015 for articles describing methods and applications of proteomics to analysis of mitochondrial proteins in kidney. Included were publications on mitochondrial proteins in kidneys of humans and animal model in health and disease.

Results and Conclusion. Proteomics of renal mitochondria has been/is mostly used in diabetes, hypertension, acidosis, nephrotoxicity and renal cancer. Integration of proteomics with other methods for examining protein activity is promising for insight into the role of renal mitochondria in pathological states. Several challenges were identified: selection of appropriate model organism, sensitivity of analytical methods and analysis of mitochondrial proteome in different renal zones/biopsies in the course of various kidney disorders.
\end{abstract}

Key words: renal mitochondria, proteomics, gel electrophoresis, liquid chromatography-mass spectrometry, diabetes, acidosis, nephrotoxicity, renal cancer

Received: October 12, 2015; Accepted with revision: March 3, 2016; Available online: March 17, 2016 http://dx.doi.org/10.5507/bp.2016.012

aBiomedical Center, Faculty of Medicine in Pilsen, Charles University in Prague, Pilsen, Czech Republic ${ }^{b}$ Department of Physiology, Faculty of Medicine in Pilsen, Charles University in Prague, Pilsen, Czech Republic 'Department of Internal Medicine I, Faculty of Medicine in Pilsen, Charles University in Prague and Teaching Hospital, Pilsen, Czech Republic Corresponding author:ZdenekTuma, e-mail:Zdenek.Tuma@lfp.cuni.cz

\section{INTRODUCTION}

Mitochondria were recognized in the cell in the $19^{\text {th }}$ century. In the first half of the $20^{\text {th }}$ century, biochemical studies were carried out on mitochondrial enzymes and pathways. Electron transport mechanisms and oxidative phosphorylation were then intensively studied ${ }^{1}$. Currently, mitochondria are known to be responsible for a variety of functions including regulation of intracellular calcium $^{2}$, generation of reactive oxygen species (ROS) (ref. ${ }^{3}$ ), production of nitric oxide ${ }^{4}$ and processes leading to cell death ${ }^{5}$.

Renal mitochondria are important as energy suppliers for active transport processes in nephrons ${ }^{6}$. Dysfunction of mitochondria caused by inherited mitochondrial cytopathies or acquired defects of proteins involved in mitochondrial metabolic pathways contributes to the pathophysiology of acute and chronic renal disorders ${ }^{7}$. Disruption of mitochondrial energetic metabolism ${ }^{7-9}$ and morphology ${ }^{10,11}$ is recognized as important contributors to tubular dysfunction in acute kidney injury (AKI). Increased production of ROS triggered by hypoxia in mitochondria during sepsis leads to kidney dysfunction and contributes to dysfunction of organs. ROS produced by mitochondria are important in the development of endothelial cell damage during focal segmental glomerulosclerosis (FSGS) $\left(\right.$ ref. $\left.^{12}\right)$. Specific impairment of renal mitochondrial metabolism has also been observed in can$\operatorname{cer}^{13}$, diabetes ${ }^{14,15}$ and as a consequence of toxic metabolite removal ${ }^{16}$. Emerging evidence also suggests that mitochondria represent a promising target for novel treatments ${ }^{17-19}$.

Proteomics was initially defined as an effort to identify and describe the complete set of proteins expressed in biological systems. Nowadays, proteomics include the study of protein-protein interactions, subcellular locations, expression levels, and posttranslational modifications of all proteins within cells and tissues. Hence, the proteomics of mitochondria is a powerful tool for understanding the mechanism of mitochondrial response to pathological conditions, evaluating the effects of drugs and for the development of new mitochondria-targeted therapies ${ }^{20,21}$. Proteomic analysis of renal mitochondria represents a multi-step process that starts with selection of appropriate biological sample and optional reduction of complexity. The next step is a combination of separation methods and mass spectrometry for qualitative and quantitative analysis of proteins and their identification. Data on changes in expression of mitochondrial enzymes, posttranslational modifications, and subunit structure of protein complexes are acquired. The purpose of this review is to provide an update on the methodological progress and potential of the rapidly evolving mitochondrial proteomics approach to facilitate new discoveries in the field of renal pathology. 


\section{Sample preparation}

For studies of renal mitochondrial proteome, tissue samples acquired from animal models or human tissues after resection are used. Renal biopsies are challenging due to small size and therefore limited amount of mitochondrial protein available. Cell cultures as an alternative to laboratory animals are useful for investigation of processes in specific renal cell types ${ }^{22}$.

Organized distribution of nephrons in renal tissue results in formation of regions with different biochemical and metabolic properties. Differences in the activity of mitochondrial enzymes along the nephron reflect the heterogeneity of the mitochondrial population in nephron segments ${ }^{23}$. Therefore, separation of kidney regions (e.g. cortex and medulla) or individual nephron segments is an alternative for reducing sample complexity. Nephron segments dissected from kidney slices ${ }^{24}$, proximal and distal tubules isolated from renal cortex by collagenase digestion and centrifugation on density gradient ${ }^{25,26}$, or glomeruli isolated by standard sieving method ${ }^{27}$ have been used for detailed study of metabolism. These separation methods may also be useful for proteomic studies on renal mitochondria. Using laser capture microdissection, selected cell populations from complex tissue sections can be acquired with high specificity. However, only a part of total cell protein is from mitochondria, and hence sensitive analytical techniques are necessary for using this procedure in the analysis of mitochondria from nephron segments.

Differential centrifugation is often used for separation of mitochondria from cells or tissue homogenates ${ }^{28}$. Isolation of mitochondria is performed in two centrifugation steps - removing of nuclei, cell membranes and unbroken cells in the first centrifugation step and sedimentation of mitochondria in the second step. A pellet that contains the mitochondrial fraction of the cell can be used for proteomic analysis directly ${ }^{29,30}$ or after purification of mitochondria by centrifugation in density gradients $^{31,32}$. In purified mitochondria, proteins from other organelles (e.g. endoplasmic reticulum, peroxisomes and cytoskeleton) still may be present due to association of these organelles with mitochondria ${ }^{33}$. Analysis of markers of subcellular compartments by Western blotting is used for determination of purity of isolated mitochondrial fractions. Further, subcellular localization of identified proteins can be checked in databases of mitochondrial proteins ${ }^{34}$ or by systems that predict subcellular localization $^{35}$. Commercially available kits based on differential centrifugation can simplify and speed up the separation and could be an alternative approach when limited amounts of sample are available or for processing large numbers of samples ${ }^{36}$.

Alternatives to differential centrifugation are separation of mitochondria using magnetic microbeads of free flow electrophoresis. Using free flow electrophoresis, high purity of mitochondria can be reached ${ }^{37}$. Low yield and the necessity for specialized equipment are major drawbacks of free flow electrophoresis ${ }^{36}$. Mitochondria can be isolated with enrichment and purity comparable to ultracentrifugation methods using magnetic microbeads ${ }^{38}$.

\section{Methods for analysis of mitochondrial proteome}

The mammalian mitochondrial proteome comprises approximately 1500 proteins $^{39,40}$. Most of them are encoded by the nuclear genome and imported into mitochondria. Only 13 protein chains of electron transport system (ETS) subunits are encoded by the mitochondrial DNA.

Mitochondrial proteome contains proteins with a wide range of hydrophobicity. Membrane proteins form a significant part of mitochondrial proteins and are a challenge for separation methods used in proteomics. These proteins are attached to the membrane in hydrophobic regions (e.g. ETS complexes ${ }^{41-44}$, electron transferring flavoprotein ${ }^{45}$ ), or embedded in the membrane (e.g. pore forming proteins). Relatively soluble enzymes are present in mitochondrial matrix ${ }^{46}$ and intermembrane space ${ }^{47}$. A significant part of mitochondrial proteins is associated into homo- or heterooligomeric protein complexes whose subunit composition is important for their function ${ }^{30}$. Analysis subunit composition and stoichiometry of mitochondrial protein complexes requires analysis under native conditions to prevent their dissociation. At present, there is no universal proteomic method that can cover all aspects of mitochondrial proteins. Proteomic workflows based on two-dimensional electrophoresis, blue native electrophoresis and gel-free chromatographic methods have been used for analysis of mitochondria. A short summary of methods used for the analysis of mitochondrial proteome is shown in Table 1.

Two-dimensional electrophoresis (2-DE) combines separation of proteins according to their net charge by isoelectric focus in the first step and by molecular weight on polyacrylamide gel in the second dimension. Proteins resolved as spots on gels are then visualized using visible or fluorescent stains and digital images of gels are acquired using a scanner or camera. With 2-DE, fast resolution of soluble proteins with the option of direct evaluation of their isoelectric points and molecular weights can be done. The use of 2-DE for mitochondrial proteomics is limited by resolution of proteins with extreme isoelectric point and molecular weight values, poor separation of hydrophobic membrane proteins, and limited detection of low abundance proteins ${ }^{48,49}$. Two-dimensional fluorescence difference gel electrophoresis (2D-DIGE) is a variant of 2-DE that improves reproducibility ${ }^{50}$. 2D-DIGE relies on labeling of samples with spectrally resolvable fluorescent cyanine dyes (Cy2, Cy3, and $\mathrm{Cy} 5)$ and their simultaneous separation on a single polyacrylamide gel. Internal standard prepared by mixing equal amount of each sample is labeled by $\mathrm{Cy} 2$; dyes $\mathrm{Cy} 3$ and $\mathrm{Cy} 5$ are then used for labeling individual samples. Internal standard and two individual samples are mixed together, separated by 2DE, and gels are scanned with the excitation wavelength of each dye used. The use of internal standard in DIGE minimizes inter-gel variability and makes processing of gel images easier ${ }^{50}$. Images are then imported to a specialized 2-DE image analysis software that allows spot detection, and quantification by calculation of the spot volumes ${ }^{51}$. Spots of interest are then excised and proteins are identified by combination of in gel digestion and mass spectrometry. 
Table 1. Summarization of proteomic methods and their suitability for analysis of mitochondrial proteome.

\begin{tabular}{|c|c|c|c|}
\hline Method & Principle & Advantages & Disadvantages \\
\hline $\begin{array}{l}\text { Two-dimensional } \\
\text { electrophoresis ( } 2 \mathrm{DE})\end{array}$ & $\begin{array}{l}\text { Separation of proteins } \\
\text { according to their net charge } \\
\text { by isoelectric focusing followed } \\
\text { by separation according their } \\
\text { masses by polyacrylamide gel } \\
\text { electrophoresis. }\end{array}$ & $\begin{array}{l}\text { Widespread, robust, relatively } \\
\text { simple method. Compatibility } \\
\text { with subsequent analyses (e.g. } \\
\text { immunochemic detection, mass } \\
\text { spectrometry). }\end{array}$ & $\begin{array}{l}\text { Difficult separation of } \\
\text { hydrophobic, extremely } \\
\text { acidic or basic proteins. } \\
\text { Limited dynamic range. } \\
\text { Low throughput, labor- } \\
\text { intensiveness. }\end{array}$ \\
\hline $\begin{array}{l}\text { Two-dimensional } \\
\text { fluorescence difference } \\
\text { gel electrophoresis } \\
\text { (DIGE) }\end{array}$ & $\begin{array}{l}\text { Labeling of samples with } \\
\text { fluorescent dyes and } \\
\text { separation on one gel with } \\
\text { internal standard by 2DE. }\end{array}$ & $\begin{array}{l}\text { Improved reproducibility and less } \\
\text { sample demand in comparison } \\
\text { with } 2 \mathrm{DE} \text {. }\end{array}$ & $\begin{array}{l}\text { Difficult separation of } \\
\text { hydrophobic and extremely } \\
\text { acidic or basic proteins. } \\
\text { Labor- intensiveness }\end{array}$ \\
\hline $\begin{array}{l}\text { Blue native } \\
\text { polyacrylamide gel } \\
\text { electrophoresis } \\
\text { (BN-PAGE) }\end{array}$ & $\begin{array}{l}\text { Separation of protein extract } \\
\text { on polyacrylamide gel in } \\
\text { presence of Coomassie } \\
\text { Brilliant Blue. }\end{array}$ & $\begin{array}{l}\text { Analysis of subunit composition } \\
\text { of protein complexes. Analysis } \\
\text { of hydrophobic complexes. } \\
\text { Maintaining activity of protein } \\
\text { complexes during separation. }\end{array}$ & $\begin{array}{l}\text { Low throughput and labor- } \\
\text { intensiveness. Only protein } \\
\text { complexes are detected. }\end{array}$ \\
\hline $\begin{array}{l}\text { Gel free methods } \\
\text { (LC-MS) }\end{array}$ & $\begin{array}{l}\text { Digestion of a complex } \\
\text { protein sample, separation } \\
\text { of proteolytic peptides by } \\
\text { one- or multiple-step of liquid } \\
\text { chromatography, on-line mass } \\
\text { spectrometric analysis of } \\
\text { eluted peptides. }\end{array}$ & $\begin{array}{l}\text { In comparison with gel based } \\
\text { methods, less sample requirement } \\
\text { and better detection of } \\
\text { hydrophobic proteins. Ability to } \\
\text { analyze very complex samples } \\
\text { by employing multidimensional } \\
\text { chromatographic separation. }\end{array}$ & $\begin{array}{l}\text { Incomplete sequence } \\
\text { coverage of identified } \\
\text { proteins. Low efficiency to } \\
\text { detect posttranslationally } \\
\text { modified peptides without } \\
\text { enrichment. }\end{array}$ \\
\hline Microarrays & $\begin{array}{l}\text { Detection of proteins } \\
\text { captured on surfaces with } \\
\text { specific antibodies or surfaces } \\
\text { optimized for capture of } \\
\text { certain protein types. }\end{array}$ & $\begin{array}{l}\text { High throughput. } \\
\text { Analysis of specific molecules by } \\
\text { selection of different array types } \\
\text { (e.g. posttranslationally modified } \\
\text { proteins). }\end{array}$ & $\begin{array}{l}\text { Number of targets is limited } \\
\text { by the selected array. } \\
\text { Cross reactivity in complex } \\
\text { protein mixtures. }\end{array}$ \\
\hline
\end{tabular}

Blue native polyacrylamide gel electrophoresis (BNPAGE) was designed for separation of intact protein complexes. Hydrophobic proteins and complexes are solubilized with a nonionic detergent. Coomassie blue added to sample and cathode buffer bounds to hydrophobic proteins and complexes and gives them a negative charge $\mathrm{e}^{52,53}$. In two dimensional setup, separation in second dimension in the presence of sodium dodecylsulfate under denaturing conditions allows resolution of subunits of individual complexes $^{54}$. These methods are utilized for investigation of respiratory complexes and their subunit composition in health and disease.

Methods utilizing a combination of high performance liquid chromatography with mass spectrometry (LCMS) are used with increasing tendency in proteomics for qualitative and quantitative analyses of complex protein mixtures extracted from biological samples; they can be also used for identification of proteins in spots from gel electrophoreses. Protein mixture extracted from a biological sample is digested by proteolytic enzyme and resulting peptides are then separated by high performance liquid chromatography. Proteolytic digestion of complex samples results in huge number of proteolytic peptides and multidimensional fractionation of peptides based on combination of two or more chromatographic steps (e.g., reverse phase liquid chromatography, ion exchange chro- matography) (ref. ${ }^{55}$ ) offers increased separation capacity and higher resolution. Separated peptides are eluted from the column directly into the mass spectrometer. During the whole chromatographic run, masses of eluting peptides and their fragmentation spectra are recorded by the mass spectrometer. These data are then used for identification of proteins and for their quantification. For quantification of proteins, label free workflows or isotopic labeling are used ${ }^{56}$. Strategies for label free quantification include two distinct groups: measurement based on measurement of area under the curve or signal intensity of precursor ion spectra, and spectral counting in which the number of fragment spectra identifying peptides from a given protein is used to assess relative protein abundance $^{57}$. Quantification by isotopic labeling is based on incorporating of isotopic compound either metabolically by incorporation of specific isotopes, or enzymatically or chemically using reagents that bound to peptides ${ }^{58,59}$. Labeled samples are combined and subjected to analysis by liquid chromatography and mass spectrometry. Quantitative data are extracted from the intensities of characteristic ions in tandem mass spectra ${ }^{59}$. Advantage of gel free attempts for analysis of mitochondrial proteome is improved detection of membrane proteins that are underrepresented in 2-DE analyses ${ }^{60}$. Microscale techniques that comprise protein extraction, fractionation and pro- 
teolytic digestion optimized for the microgram protein range would allow analysis of small samples of mitochondria from biopsies or nephron segments ${ }^{61}$.

Protein microarrays allow simultaneous detection of a set of proteins and offer the ability to study multiple samples in an effort to develop protein profile changes across multiple proteins ${ }^{62,63}$. The ability of microarrays for screening of multiple proteins is advantageous for detection of protein expression changes, protein-protein interactions, and biomarker discovery and validation ${ }^{64}$. Analysis of intact proteins by microarrays instead of proteolytic digests can be advantageous for preservation of specific motifs but conjugation of sample with the tag necessary for subsequent detection or signal amplification may denature, damage, or mask the epitope ${ }^{65}$. Antibody cross-reactivity to non-target proteins can also decrease performance in antibody microarrays ${ }^{62,63}$. The potential for utilization of protein microarrays in analysis of renal mitochondria could be in high throughput monitoring of selected pathways by analysis of multiple, predefined set of proteins. Arrays based on mass spectrometric detection of proteins bound to affinity surfaces (surface-enhanced laser desorption and ionization, SELDI) have been used for analysis of brain mitochondria ${ }^{66,67}$. Chips with wide range of surfaces are available for SELDI. The use of chip surface optimized for binding of hydrophobic proteins could be potentially advantageous for analysis of mitochondrial membrane proteins.

\section{CLINICAL AND RESEARCH APPLICATION OF RENAL MITOCHONDRIAL PROTEOMICS}

\section{Basic characterization of renal mitochondrial proteome}

In renal tissue of various species including mouse, rat and human, mitochondrial proteins have been identified by proteomic methods ${ }^{68-70}$. Comparison of 2-DE maps of rat kidney cortex and medulla ${ }^{68}$ or human kidney cortex, medulla and glomeruli ${ }^{71}$ showed alterations in spots containing mitochondrial proteins. However, this attempt is not suitable for detailed analysis of the mitochondrial proteome due to very low amount of mitochondrial proteins detected. The coverage of mitochondrial proteome is increased when mitochondria prepared by differential centrifugation are used for analysis instead of whole tissue. Analysis of mitochondrial fractions of porcine renal cortex and medulla showed that mitochondrial proteome of the cortex contained enzymes employed in oxygen dependent pathways and mitochondrial proteome in the medulla proteins important for adaptation to low oxygen availability ${ }^{72}$. Further datasets that contain proteins of renal mitochondria are available in experiments that investigated composition of mitochondrial proteome from mouse tissues by 2-DE ( ref. $^{73}$ ) and rat organs by BN-PAGE (ref. ${ }^{30}$ ) and LC-MS (ref. ${ }^{74}$ ). High throughout proteome analysis done by LC-MS allowed characterization of multiple mitochondrial metabolic pathways ${ }^{75}$. However, translation of animal data to humans is limited by differences in anatomy, metabolism and physiology. On the other hand, several factors make the human research into renal cellular and molecular biology problematic. In particular, difficult access to the human renal tissue and several confounding factors including disease state, the patient 's comorbidities and treatment history represent main impediments to the study of human renal mitochondrial proteome. Therefore, the use of clinically relevant animal models remains a cornerstone in the study renal mitochondrial pathology. In this context, pig is highly valuable model organism due to anatomic, physiological and biochemical similarities of porcine and human kidney ${ }^{76}$.

\section{Recent advances in mitochondrial studies: a focus on selected renal pathologies}

In the following text, we summarize recent advances from various mitochondrial proteomic studies of the most common pathological states of the kidney. Short summary of utilization of these methods is also available in Table 2. Detailed analysis of all research applications of mitochondrial proteomics falls outside the scope of this work and the reader is referred to recent in-depth reviews s1,77-80. $^{2}$.

\section{Diabetes}

All forms of diabetes are characterized by hyperglycemia, a relative or absolute lack of insulin action, pathway-selective insulin resistance, and the development of diabetes-specific pathology in the retina, renal glomerulus, and peripheral nerves. Oxidative stress is a key component in the development of diabetic nephropathy. Reactive oxygen species (ROS) are produced by cytosolic (such as glycolysis, specific defects in the polyol pathway, uncoupling of nitric oxide synthase, xanthine oxidase, and advanced glycation) and mitochondrial pathways (electron leakage at complex I and at the interface between coenzyme Q and complex III) (ref. ${ }^{81}$ ). Excess amounts of ROS modulate activation of protein kinase $\mathrm{C}$, mitogen-activated protein kinases, and various cytokines and transcription factors which eventually cause increased expression of extracellular matrix genes with progression to fibrosis and end stage renal disease ${ }^{82}$. Impairment of renal mitochondria induced by oxidative stress is an important factor in diabetes; therefore mitochondria represent an important site due to their intensive oxidative metabolism and using proteomics, specific targets for therapy in mitochondria can be revealed.

Proteomic analysis showed upregulation of TCA cycle and fatty acid oxidation proteins by analysis cytosolic compartment of kidney cortex ${ }^{83}$ and renal mitochondria ${ }^{84}$ of diabetic mice. Increased level of mitochondrial fatty acid metabolism enzymes in renal cortex of diabetic animals supported the hypothesis that insulin resistance can be attributed to increases in intracellular fatty acid metabolites that disrupted insulin signaling ${ }^{83}$.

Increased expression of mitochondrial 3-hydroxy3-methylglutaryl-CoA synthase 2 (HMGCS2) was found using 2-DE analysis in kidney of diabetic mice. It was proposed that excess of ketogenic activity resulting from 
Table 2. Applications of proteomic methods that were used in studies of the most common pathological states of the kidney.

\begin{tabular}{|c|c|c|c|}
\hline Pathology & Method & Sample, organism & What was studied \\
\hline \multirow[t]{2}{*}{ Diabetes } & 2-DE & $\begin{array}{l}\text { Kidney tissue, mouse } e^{83,85} \text {. } \\
\text { Mitochondria, mouse }{ }^{86} \text {. } \\
\text { Mitochondria, rat }{ }^{15} \text {. }\end{array}$ & $\begin{array}{l}\text { Changes of proteome during diabetes }{ }^{83} \text {. } \\
\text { Proteomic profile of kidney and identification of mitochondrial ketogenic } \\
\text { enzyme }^{85} \text {. } \\
\text { Posttranslational modification of mitochondrial proteome }{ }^{86,15} \text {. }\end{array}$ \\
\hline & LC-MS & $\begin{array}{l}\text { Mitochondria, mouse }{ }^{84} \text {. } \\
\text { Kidney tissue, } \text { rat }^{87}\end{array}$ & $\begin{array}{l}\text { Changes of protein expression during diabetes }{ }^{84} \text {. } \\
\text { Identification of potential therapy targets }{ }^{87} \text {. }\end{array}$ \\
\hline \multirow[t]{2}{*}{ Hypertension } & 2-DE & Kidney tissue, rat ${ }^{93}$. & Protein expression profile in a model of hypertension ${ }^{93}$. \\
\hline & LC-MS & Mitochondria, rat ${ }^{94}$. & Mitochondrial metabolism in mitochondria in a model of hypertension ${ }^{94}$. \\
\hline \multirow[t]{2}{*}{ Acidosis } & 2D-DIGE & Proximal tubules, rat $^{95}$. & Changes in protein expression during acidosis ${ }^{95}$. \\
\hline & LC-MS & Mitochondria, rat ${ }^{29}$. & $\begin{array}{l}\text { Response of the mitochondrial proteome of renal proximal convoluted } \\
\text { tubules to chronic metabolic acidosis }{ }^{29} \text {. }\end{array}$ \\
\hline $\begin{array}{l}\text { Acute kidney } \\
\text { injury }\end{array}$ & $\begin{array}{l}\text { Western } \\
\text { blotting }\end{array}$ & Kidney tissue, mouse ${ }^{17,96}$. & $\begin{array}{l}\text { Expression of mitochondrial protein after treatment of AKI by antioxidant }{ }^{17} \text {. } \\
\text { Protective mechanism of mitochondrial sirtuin }{ }^{96} \text {. }\end{array}$ \\
\hline Nephrotoxicity & 2-DE & $\begin{array}{l}\text { Kidney tissue, rat }{ }^{98,99} \\
\text { Cell culture } \\
\text { Mitochondria }^{22}\end{array}$ & $\begin{array}{l}\text { Interaction of gentamicin }{ }^{98} \text { and cyclosporine } \mathrm{A}^{99} \text { with kidney. } \\
\text { Effect of calcium oxalate monohydrate }{ }^{101,22} \text { and dihydrate }{ }^{102} .\end{array}$ \\
\hline \multirow[t]{3}{*}{ Renal cancer } & 2-DE & $\begin{array}{l}\text { Tissue, human } \\
\text { Mitochondria, human } \\
\text { Cell culture, } \text { human }^{108}\end{array}$ & $\begin{array}{l}\text { Protein profiles of tissue and tumor }{ }^{104} \text {. } \\
\text { Mitochondrial proteomes of different tumors }{ }^{105} \text {. } \\
\text { Impact of cisplatin administration on protein expression levels }{ }^{108} \text {. }\end{array}$ \\
\hline & 2D-DIGE & Tumor tissue, human ${ }^{107}$. & Stage-related changes of proteins in tumors ${ }^{107}$. \\
\hline & BN-PAGE & Tumor tissue, human ${ }^{106}$ & Composition of ETS complexes in tumors ${ }^{106}$. \\
\hline
\end{tabular}

increased expression of HMGCS2 contributes to diabetic nephropathy and HMGCS2 may therefore represent a potential therapeutic target ${ }^{85}$.

Proteomic analysis of cytosolic and mitochondrial fractions of diabetic mice kidney provided data about migration of mitochondrial proteins ${ }^{86}$. Increased amount of prohibitin and cytochrome c was detected in cytosolic fraction of diabetic kidney. Mitochondrial prohibitin is involved in cell cycle function and its increased amount in cytoplasmic fraction was attributed to damage of mitochondrial membrane or impaired transport into mitochondrion. The leakage of cytochrome $\mathrm{c}$ into cytosol indicated alteration in permeability of mitochondrial membrane.

In diabetes, high blood glucose level results in posttranslational modifications of proteins. Proteins modified by methylglyoxal (MGO) were found in renal mitochondria of diabetic rats and identified as enzymes of beta oxidation and subunits of ETS complex I and III. It was shown that activity of complex III was decreased due to its modification by MGO (ref. ${ }^{15}$ ).

Effect of triethylenetetramine (TETA) on mitochondria of diabetic kidney was studied by proteomics ${ }^{87}$. TETA is a copper chelator that prevents or reverses diabetic copper overload and thereby suppress oxidative stress. Analysis of kidney of diabetic animals revealed that treatment by TETA restored decrease of mitochondrial chaperones involved in protein turnover and assembly, and enzymes involved in oxidative phosphorylation and mitochondrial fatty acid metabolism expression caused by diabetes ${ }^{87}$.

\section{Hypertension}

Essential hypertension is a heterogeneous disorder in which both genetics and environmental factors contribute to increased cardiovascular and renal morbidity and mortality ${ }^{88}$. Changes in renal mitochondria in rat models of hypertension include alterations in respiratory functions ${ }^{89}$ and oxidative stress ${ }^{90,91}$ and renal mitochondria represent possible therapeutic target ${ }^{92}$.

Protein expression profiles of the kidney in spontaneously hypertensive rats revealed decreased expression of NADPH dependent mitochondrial isocitrate dehydrogenase ${ }^{93}$. Decreased defense against mitochondrial oxidative damage in hypertensive rats was suggested due to involvement of this protein in process of glutathione regeneration.

Using salt-sensitive rats as model organism for hypertension, effect of salt-induced hypertension on mitochondria of thick ascending limb of Henle's loop was tested by proteomics ${ }^{94}$. Downregulation of proteins connected with energy metabolism predicted reduction of oxygen utilization in mitochondria in medullary thick ascending limb of Henle's loop of salt sensitive rats ${ }^{94}$. 


\section{Acidosis}

Metabolic acidosis is caused by overproduction of an acid or reduced recovery of bicarbonate. Adaptive response of renal proximal tubule includes rapid increase of ammoniagenesis and gluconeogenesis. In proximal tubules of acidotic rats, increased levels of mitochondrial proteins associated with catabolism of plasma glutamine were detected by proteomics using 2D-DIGE (ref. ${ }^{95}$ ). These changes in protein expression levels contributed significantly to the adaptive response to metabolic acidosis and/or renal hypertrophy. In mitochondria of rat proximal convoluted tubules ${ }^{29}$, abundance of proteins including mitochondrial enzymes involved in glutamine metabolism and acid-base balance was significantly altered in response to metabolic acidosis. During acidosis, increased acetylation of mitochondrial proteins was detected and it was hypothesized that acetylation may prevent protein degradation by blocking sites of ubiquitination.

\section{Acute kidney injury}

In experimental models of AKI, abnormal mitochondrial biogenesis, fission/fusion, and autophagy have been characterized and recovery of mitochondrial functions was found to be important for function of the kidney ${ }^{11}$. Ischemia-reperfusion injury in AKI contributes to fragmentation of mitochondria and processes leading to cell death ${ }^{10}$. Although proteomic analysis of mitochondria or kidney tissue affected by AKI is not available to date, experimental data suggest that changes in mitochondrial proteins structure and activity could substantially contribute to the onset or progress of renal dysfunction associated with AKI (ref. ${ }^{17}$ ). Recent research showed that mitochondrial proteins could be an important target for therapy ${ }^{96,97}$. Therefore, proteomic analysis of mitochondria on model systems during AKI could bring important information about mechanisms of mitochondrial damage and reveal potential therapeutic targets.

\section{Detection of nephrotoxic compounds effect}

Kidney plays an important role in elimination of xenobiotics, including drugs and toxic environmental agents. During concentration of urine, tubular structures of nephrons are exposed to relative high concentrations of xenobiotic compounds. Knowledge of putative interactions of xenobiotics, drugs or their metabolites with renal mitochondria could help to prevent potential damage to the kidney.

Proteomic analysis of renal cortex was performed to delineate the effects of gentamicin ${ }^{98}$. Gentamicin belongs to aminoglycosides which are known to inhibit sodium and potassium ATPase activity. The analysis revealed that expression of mitochondrial proteins employed in gluconeogenesis and glycolysis, fatty acid utilization and TCA cycle was affected by gentamicin.

Effect of cyclosporine A (CsA) nephrotoxicity was studied on the kidney of normal and salt-depleted rat models by combined strategy employing proteomics and metabolomics ${ }^{99}$. CsA is used after renal transplantation to prevent organ rejection. Mitochondrial proteins of oxidative phosphorylation and fatty acid $\beta$-oxidation were upregulated in low-salt control rats compared to normalfed animals. Upregulation of these proteins suggested increased energy demand, possibly for retaining normal osmolarity within the cells. In low salt animals, CsA treatment decreased the level of TCA cycle and ETS proteins. CsA more strongly affected the kidneys of rats fed with a low-salt diet due to their higher dependence on the energy production by mitochondrial respiration ${ }^{99}$.

In hyperoxaluria, renal tubular epithelial cells are exposed to oxalate which lead to the activation of intracellular responses, including overproduction of free radicals and reactive oxygen species. Mitochondrial dysfunction is an important event favoring kidney stone formation ${ }^{100}$. In renal tubular epithelial cells incubated with calcium oxalate monohydrate $(\mathrm{COM})$ (ref. ${ }^{101}$ ) or calcium oxalate dihydrate (COD) (ref. ${ }^{102}$ ), changes in expression of several mitochondrial proteins were detected. Proteomic analysis of mitochondria ${ }^{22}$ revealed that COM treatment affected enzymes of cell cycle regulation, carbohydrate, amino acid and energy metabolism. Increased level of oxidatively modified proteins indicated ROS overproduction in COM treated cells. Proteomic approach documented a complex effect of COM crystals on renal cells and showed that mitochondrial pathways of energy metabolism, ROS regulation and oxidative stress response were affected.

\section{Renal cancer}

In tumors, energy metabolism is shifted from oxidative phosphorylation to glycolysis. However, synthetic pathways in mitochondria are still important for cancer cells and mitochondria represent important targets for therapy ${ }^{103}$. Increased expression of glycolytic proteins and downregulation of mitochondrial gluconeogenic enzymes that reflect the predominance of glycolysis followed by lactic acid fermentation in the presence of adequate oxygen (Warburg effect) in was detected in renal carcinoma tissue ${ }^{104}$. Analysis of mitochondria isolated from renal oncocytoma and chromophobe cell carcinoma was performed by 2-DE (ref. ${ }^{105}$ ). Differences in abundance of ETS subunits, proteins of glycolysis, beta oxidation and antioxidant proteins have been found.

Analyses by BN-PAGE can reveal alterations and abundance of ETS protein complexes in renal tumor tissues in comparison with healthy tissue or between tumor types. Using BN-PAGE, differences in patterns of ETS complexes in three types of renal tumors were examined ${ }^{106}$. It was found that decreased amount of ETS complexes II, III IV and ATP synthase correlated with aggressiveness of renal cell carcinoma.

Recent evidence showed that mitochondrial proteome is changed during tumor progression ${ }^{107}$. Samples of renal cell carcinoma of different stages have been analyzed by 2D-DIGE. Mitochondrial proteins of TCA cycle and ETS system were found to be downregulated according to Warburg hypothesis. Mitochondrial prohibitin and peroxiredoxin-3 showed stage-dependent changes in expression and may be used as potential markers of progression.

Compounds used for anticancer therapy may influence the mitochondrial proteins ${ }^{108}$. Cisplatin is an important anticancer drug and its use is frequently limited by 
various significant side effects including nephrotoxicity ${ }^{109}$. Proteome analysis of renal cells incubated with cisplatin identified changes in several mitochondrial proteins. Upregulation of mitochondrial heat shock protein HSP70 may indicate a defense mechanism against apoptosis. Increase of glycolytic enzyme glyceraldehyde 3-phosphate dehydrogenase was attributed to compensatory effect on disturbed mitochondrial oxidative processes and decrease of mitochondrial superoxide dismutase to decreased activity of free radical defense mechanisms ${ }^{108}$.

\section{CONCLUSION AND RESEARCH PERSPECTIVES}

Proteomic analyses of renal mitochondria holds great potential for providing information on remodeling of mitochondrial metabolic pathways, protein posttranslational modifications and composition of mitochondrial protein complexes during various renal pathological states. These data can be then used for investigating the pathophysiology of diseases associated with mitochondrial dysfunction and for revealing potential targets for therapy. Nevertheless, many challenges remain. We have developed the following research agenda in relation to the renal mitochondrial proteomics aimed to identify potential research questions to address the existing knowledge gaps.

- Complex structure of kidney tissue is an important factor for analysis of the renal mitochondrial proteome; therefore the important step is the reduction of sample complexity by isolation of renal cortex, medulla, nephron segments and isolation of mitochondria.

- Analysis of mitochondria in renal biopsies represents a significant challenge due to low amount of available protein. Optimization of methods for isolation of mitochondria in high purity and analytical methods for covering wide range of hydrophobicity, abundance and posttranslational modifications of mitochondrial proteome is important.

- Combination of proteomics with methods that reflect metabolic activity (e.g. metabolomics, high resolution respirometry) can provide more detailed understanding of renal mitochondrial physiology and pathology.

- There is a pressing need to better understand the nature, time course and magnitude of mitochondrial proteome changes in different renal zones in the course of various kidney disorders.

- Further proteomic studies are also required to better understand how multiple comorbidities (such as diabetes, heart failure) as well as aging alter the renal mitochondrial proteome, enhance the intrinsic susceptibility of mitochondrial system to insults and how they affect the effectiveness of novel therapies.

- Due to the inaccessibility of the kidney tissue under clinical conditions, future research will need better preclinical models of $\mathrm{AKI}$ and $\mathrm{CKD}$ that recapitulate the complex nature of human disease.

\section{ABBREVIATIONS}

ATP, Adenosine triphosphate; AKI, Acute kidney injury; BN-PAGE, Blue native polyacrylamide gel electrophoresis; CKD, Chronic kidney disease; COD, Calcium oxalate dihydrate; COM, Calcium oxalate monohydrate; CsA, Cyclosporin A; ETS, Electron transport system; HMGCS2, 3-hydroxy-3-methylglutaryl-CoA synthase 2; HPLC, High performance liquid chromatography; IMM, Inner mitochondrial membrane; LC-MS, Liquid chromatography - mass spectrometry; MGO, Methylglyoxal; MPT, Mitochondrial permeability transition pore; MW, Molecular weight; OMM, Outer mitochondrial membrane; pI, Isoelectric point; ROS, Reactive oxygen species; SELDI, Surface-enhanced laser desorption and ionization; TCA, Tricarboxylic acid cycle; TETA, Triethylenetetramine; VDAC1, Voltage-dependent anionselective channel 1; VDAC2, Voltage-dependent anion-selective channel 2; 2-DE, Two-dimensional electrophoresis; 2D-DIGE, Two-dimensional fluorescence difference gel electrophoresis.

Acknowledgment: This work was supported by the National Sustainability Program I (NPU I) Nr. LO1503 provided by the Ministry of Education Youth and Sports of the Czech Republic, the Charles University Research Fund (project number P36), and the Specific Student Research Project no. 260175/2015 of the Charles University in Prague.

Author contributions: ZT, JK, JM, MG, MM: literature search; ZT, JK, MM: manuscript writing, ZT, JK, JM, MG, MM: final approval.

Conflict of interest statement: The authors state that there are no conflicts of interest regarding the publication of this article.

\section{REFERENCES}

1. Ernster L, Schatz G. Mitochondria: a historical review. The Journal of cell biology 1981;91(3 Pt 2):227s-255s.

2. Dedkova EN, Blatter LA. Mitochondrial Ca2+ and the heart. Cell calcium 2008;44(1):77-91.

3. Murphy MP. How mitochondria produce reactive oxygen species. The Biochemical journal 2009;417(1):1-13.

4. Nisoli E, Carruba MO. Nitric oxide and mitochondrial biogenesis. Journal of cell science 2006;119(Pt 14):2855-62.

5. Kroemer G, Reed JC. Mitochondrial control of cell death. Nature medicine 2000;6(5):513-19.

6. Yasuda M, Fujita T, Higashio T, Okahara T, Abe Y, Yamamoto K. Effects of 4-pentenoic acid and furosemide on renal functions and renal uptake of individual free fatty acids. Pflugers Archiv : European journal of physiology 1980;385(2):111-6.

7. Che R, Yuan Y, Huang S, Zhang A. Mitochondrial dysfunction in the pathophysiology of renal diseases. American journal of physiology. Renal physiology 2014;306(4):F367-78.

8. Funk JA, Schnellmann RG. Persistent disruption of mitochondrial homeostasis after acute kidney injury. American journal of physiology. Renal physiology 2012;302(7):F853-64.

9. Gomez H, Ince C, De Backer D, Pickkers P, Payen D, Hotchkiss J, Kellum JA. A unified theory of sepsis-induced acute kidney injury: inflammation, microcirculatory dysfunction, bioenergetics, and the tubular cell adaptation to injury. Shock 2014;41(1):3-11.

10. Hall AM. Maintaining mitochondrial morphology in AKI: looks matter. Journal of the American Society of Nephrology 2013;24(8):1185-7. 
11. Stallons LJ, Funk JA, Schnellmann RG. Mitochondrial Homeostasis in Acute Organ Failure. Current pathobiology reports 2013;1(3):169-77.

12. Daehn I, Casalena G, Zhang T, Shi S, Fenninger F, Barasch N, Yu L, D'Agati V, Schlondorff D, Kriz W, Haraldsson B, Bottinger EP. Endothelial mitochondrial oxidative stress determines podocyte depletion in segmental glomerulosclerosis. The Journal of clinica investigation 2014;124(4):1608-21.

13. Gogvadze V, Orrenius S, Zhivotovsky B. Mitochondria in cancer cells: what is so special about them? Trends in cell biology 2008;18(4):16573.

14. Rolo AP, Palmeira CM. Diabetes and mitochondrial function: role of hyperglycemia and oxidative stress. Toxicology and applied pharmacology 2006;212(2):167-78.

15. Rosca MG, Mustata TG, Kinter MT, Ozdemir AM, Kern TS, Szweda LI, Brownlee M, Monnier VM, Weiss MF. Glycation of mitochondria proteins from diabetic rat kidney is associated with excess superoxide formation. American journal of physiology. Renal physiology 2005;289(2):F420-30.

16. Izzedine H, Launay-Vacher V, Deray G. Antiviral drug-induced nephrotoxicity. American journal of kidney diseases 2005;45(5):804-17.

17. Patil NK, Parajuli N, MacMillan-Crow LA, Mayeux PR. Inactivation of renal mitochondrial respiratory complexes and manganese superoxide dismutase during sepsis: mitochondria-targeted antioxidant mitigates injury. American journal of physiology. Renal physiology 2014;306(7):F734-43

18. Papazova DA, Friederich-Persson M, Joles JA, Verhaar MC. Renal transplantation induces mitochondrial uncoupling, increased kidney oxygen consumption, and decreased kidney oxygen tension. American journal of physiology. Renal physiology 2015;308(1):F22-8.

19. Saba H, Batinic-Haberle I, Munusamy S, Mitchell T, Lichti C, Megyesi J MacMillan-Crow LA. Manganese porphyrin reduces renal injury and mitochondrial damage during ischemia/reperfusion. Free radical biology \& medicine 2007;42(10):1571-8.

20. Jiang $Y$, Wang $X$. Comparative mitochondrial proteomics: perspective in human diseases. Journal of hematology \& oncology 2012;5:11.

21. Peinado JR, Diaz-Ruiz A, Fruhbeck G, Malagon MM. Mitochondria in metabolic disease: getting clues from proteomic studies. Proteomics 2014;14(4-5):452-66

22. Chaiyarit S, Thongboonkerd V. Changes in mitochondrial proteome of renal tubular cells induced by calcium oxalate monohydrate crystal adhesion and internalization are related to mitochondrial dysfunction. Journal of proteome research 2012;11(6):3269-80.

23. Guder WG, Ross BD. Enzyme distribution along the nephron. Kidney international 1984;26(2):101-11.

24. Klein KL, Wang MS, Torikai S, Davidson WD, Kurokawa K. Substrate oxidation by isolated single nephron segments of the rat. Kidney international 1981;20(1):29-35.

25. Doctor RB, Chen J, Peters LL, Lux SE, Mandel LJ. Distribution of epithelial ankyrin (Ank3) spliceoforms in renal proximal and distal tubules. The American journal of physiology 1998;274(1 Pt 2):F129-38.

26. Walmsley SJ, Broeckling C, Hess A, Prenni J, Curthoys NP. Proteomic analysis of brush-border membrane vesicles isolated from purified proximal convoluted tubules. American journal of physiology. Renal physiology 2010;298(6):F1323-31.

27. Yoshida Y, Miyazaki K, Kamiie J, Sato M, Okuizumi S, Kenmochi A, Kamijo K, Nabetani T, Tsugita A, Xu B, Zhang Y, Yaoita E, Osawa T, Yamamoto T. Two-dimensional electrophoretic profiling of normal human kidney glomerulus proteome and construction of an extensible markup language (XML)-based database. Proteomics 2005;5(4):1083-96

28. Graham JM. Isolation of mitochondria from tissues and cells by differential centrifugation. Current protocols in cell biology 2001;Chapter 3:Unit 3.3.

29. Freund DM, Prenni JE, Curthoys NP. Response of the mitochondrial proteome of rat renal proximal convoluted tubules to chronic metabolic acidosis. American journal of physiology. Renal physiology 2013;304(2):F145-55

30. Reifschneider NH, Goto S, Nakamoto H, Takahashi R, Sugawa M, Dencher NA, Krause F. Defining the mitochondrial proteomes from five rat organs in a physiologically significant context using 2D bluenative/SDS-PAGE. Journal of proteome research 2006;5(5):1117-32.

31. Graham JM. Purification of a crude mitochondrial fraction by density-gradient centrifugation. Current protocols in cell biology 2001; Chapter 3:Unit 3.4.
32. Sims NR, Anderson MF. Isolation of mitochondria from rat brain using Percoll density gradient centrifugation. Nat. Protoc. 2008;3(7):122839.

33. Raturi A, Simmen T. Where the endoplasmic reticulum and the mitochondrion tie the knot: the mitochondria-associated membrane (MAM). Biochimica et biophysica acta 2013;1833(1):213-24.

34. Andreoli C, Prokisch H, Hortnagel K, Mueller JC, Munsterkotter M, Scharfe C, Meitinger T. MitoP2, an integrated database on mitochondrial proteins in yeast and man. Nucleic Acids Res 2004;32(Database issue):D459-62

35. Gaston D, Tsaousis AD, Roger AJ. Predicting proteomes of mitochondria and related organelles from genomic and expressed sequence tag data. Methods in enzymology 2009;457:21-47.

36. Hartwig S, Feckler C, Lehr S, Wallbrecht K, Wolgast H, MullerWieland D, Kotzka J. A critical comparison between two classical and a kit-based method for mitochondria isolation. Proteomics 2009;9(11):3209-14.

37. Eubel H, Lee CP, Kuo J, Meyer EH, Taylor NL, Millar AH. Free-flow electrophoresis for purification of plant mitochondria by surface charge. The Plant journal : for cell and molecular biology 2007;52(3):583-94.

38. Hornig-Do HT, Gunther G, Bust M, Lehnartz P, Bosio A, Wiesner RJ. Isolation of functional pure mitochondria by superparamagnetic microbeads. Analytical biochemistry 2009;389(1):1-5.

39. Lopez MF, Kristal BS, Chernokalskaya E, Lazarev A, Shestopalov AI, Bogdanova A, Robinson M. High-throughput profiling of the mitochondrial proteome using affinity fractionation and automation. Electrophoresis 2000;21(16):3427-40.

40. Taylor SW, Fahy E, Zhang B, Glenn GM, Warnock DE, Wiley S, Murphy AN, Gaucher SP, Capaldi RA, Gibson BW, Ghosh SS. Characterization of the human heart mitochondrial proteome. Nature biotechnology 2003;21(3):281-6.

41. Cecchini G. Function and structure of complex II of the respiratory chain. Annual review of biochemistry 2003;72:77-109.

42. Hirst J. Why does mitochondrial complex I have so many subunits? The Biochemical journal 2011;437(2):e1-3.

43. Iwata S, Lee JW, Okada K, Lee JK, Iwata M, Rasmussen B, Link TA Ramaswamy S, Jap BK. Complete structure of the 11-subunit bovine mitochondrial cytochrome bc1 complex. Science 1998;281(5373):6471.

44. Wittig I, Schagger H. Structural organization of mitochondrial ATP synthase. Biochimica et biophysica acta 2008;1777(7-8):592-8.

45. Watmough NJ, Frerman FE. The electron transfer flavoprotein: ubiquinone oxidoreductases. Biochimica et biophysica acta 2010;1797(12):1910-6.

46. Rhee HW, Zou P, Udeshi ND, Martell JD, Mootha VK, Carr SA, Ting AY. Proteomic mapping of mitochondria in living cells via spatially restricted enzymatic tagging. Science 2013;339(6125):1328-31.

47. Vogtle FN, Burkhart JM, Rao S, Gerbeth C, Hinrichs J, Martinou JC, Chacinska A, Sickmann A, Zahedi RP, Meisinger C. Intermembrane space proteome of yeast mitochondria. Molecular and cellular proteomics 2012;11(12):1840-52.

48. Mathy G, Sluse FE. Mitochondrial comparative proteomics: strengths and pitfalls. Biochimica et biophysica acta 2008;1777(7-8):1072-7.

49. Silvestri E, Lombardi A, Glinni D, Senese R, Cioffi F, Lanni A, Goglia F, Moreno M, de Lange P. Mammalian Mitochondrial Proteome And Its Functions: Current Investigative Techniques And Future Perspectives On Ageing And Diabetes. Journal of Integrated OMICS 2011;1(1):1727.

50. O'Connell K, Ohlendieck K. Proteomic DIGE analysis of the mitochondria-enriched fraction from aged rat skeletal muscle. Proteomics 2009;9(24):5509-24

51. Chevalier F. Highlights on the capacities of "Gel-based" proteomics. Proteome science 2010;8(1):23-32.

52. Schagger $\mathrm{H}$, von Jagow $\mathrm{G}$. Blue native electrophoresis for isolation of membrane protein complexes in enzymatically active form. Analytical biochemistry 1991;199(2):223-31.

53. Wittig I, Schagger H. Features and applications of blue-native and clear-native electrophoresis. Proteomics 2008;8(19):3974-90.

54. Nijtmans LG, Henderson NS, Holt IJ. Blue Native electrophoresis to study mitochondrial and other protein complexes. Methods 2002;26(4):327-34.

55. Zhang $X$, Fang A, Riley CP, Wang M, Regnier FE, Buck C. Multidimensional liquid chromatography in proteomics--a review. Analytica chimica acta 2010;664(2):101-13. 
56. Sjodin MO, Wetterhall M, Kultima K, Artemenko K. Comparative study of label and label-free techniques using shotgun proteomics for relative protein quantification. Journal of chromatography $B$ 2013;928:83-92.

57. Neilson KA, Ali NA, Muralidharan S, Mirzaei M, Mariani M, Assadourian G, Lee A, van Sluyter SC, Haynes PA. Less label, more free: approaches in label-free quantitative mass spectrometry. Proteomics 2011;11(4):535-53.

58. Aggarwal K, Choe LH, Lee KH. Shotgun proteomics using the iTRAQ isobaric tags. Briefings in Functional Genomics and Proteomics 2006;5(2):112-20.

59. Zhou Y, Shan Y, Zhang L, Zhang Y. Recent advances in stable isotope labeling based techniques for proteome relative quantification. Journal of chromatography A 2014;1365:1-11.

60. Tan S, Tan HT, Chung MC. Membrane proteins and membrane proteomics. Proteomics 2008;8(19):3924-32.

61. Feist $P$, Hummon AB. Proteomic challenges: sample preparation techniques for microgram-quantity protein analysis from biological samples. International journal of molecular sciences 2015;16(2):3537-63.

62. Gahoi N, Ray S, Srivastava S. Array-based proteomic approaches to study signal transduction pathways: prospects, merits and challenges. Proteomics 2015;15(2-3):218-31.

63. Pratsch K, Wellhausen R, Seitz H. Advances in the quantification of protein microarrays. Current Opinion in Chemical Biology 2014;18:16-20.

64. Ramachandran N, Srivastava S, Labaer J. Applications of protein microarrays for biomarker discovery. Proteomics. Clinical applications 2008;2(10-11):1444-59.

65. Liotta LA, Espina V, Mehta Al, Calvert V, Rosenblatt K, Geho D, Munson PJ, Young L, Wulfkuhle J, Petricoin EF, 3rd. Protein microarrays: meeting analytical challenges for clinical applications. Cancer cell 2003;3(4):317-25.

66. Azzam S, Broadwater L, Li S, Freeman EJ, McDonough J, Gregory RB. A SELDI mass spectrometry study of experimental autoimmune encephalomyelitis: sample preparation, reproducibility, and differentia protein expression patterns. Proteome science 2013;11(1):19.

67. Broadwater L, Pandit A, Clements R, Azzam S, Vadnal J, Sulak M, Yong VW, Freeman EJ, Gregory RB, McDonough J. Analysis of the mitochondrial proteome in multiple sclerosis cortex. Biochimica et biophysica acta 2011;1812(5):630-41.

68. Arthur JM, Thongboonkerd V, Scherzer JA, Cai J, Pierce WM, Klein JB. Differential expression of proteins in renal cortex and medulla: a proteomic approach. Kidney international 2002;62(4):1314-21.

69. Zhang Y, Yoshida Y, Xu B, Magdeldin S, Fujinaka H, Liu Z, Miyamoto M, Yaoita E, Yamamoto T. Comparison of human glomerulus proteomic profiles obtained from low quantities of samples by different mass spectrometry with the comprehensive database. Proteome science 2011;9(1):47.

70. Zhao Y, Denner L, Haidacher SJ, LeJeune WS, Tilton RG. Comprehensive analysis of the mouse renal cortex using two-dimensional HPLC - tandem mass spectrometry. Proteome science 2008;6(15):15

71. Xu B, Yoshida Y, Zhang Y, Yaoita E, Osawa T, Yamamoto T. Twodimensional electrophoretic profiling of normal human kidney: differential protein expression in glomerulus, cortex and medulla. Journal of Electrophoresis 2005;49(1):5-13.

72. Tuma Z, Kuncova J, Mares J, Matejovic M. Mitochondrial proteomes of porcine kidney cortex and medulla: foundation for translationa proteomics. Clinical and Experimental Nephrology 2016;20(1):39-49. doi:10.1007/s10157-015-1135-x

73. Techritz S, Lutzkendorf S, Bazant E, Becker S, Klose J, Schuelke M Quantitative and qualitative 2D electrophoretic analysis of differentially expressed mitochondrial proteins from five mouse organs. Proteomics 2013;13(1):179-95.

74. Johnson DT, Harris RA, French S, Blair PV, You J, Bemis KG, Wang $M$, Balaban RS. Tissue heterogeneity of the mammalian mitochondrial proteome. American journal of physiology. Cell physiology 2007;292(2):C689-97

75. Johnson DT, Harris RA, Blair PV, Balaban RS. Functional consequences of mitochondrial proteome heterogeneity. American journal of physiology. Cell physiology 2007;292(2):C698-707.

76. Giraud S, Favreau F, Chatauret N, Thuillier R, Maiga S, Hauet T. Contribution of large pig for renal ischemia-reperfusion and trans- plantation studies: the preclinical model. Journal of biomedicine \& biotechnology 2011;2011:532127.

77. Amado FM, Barros A, Azevedo AL, Vitorino R, Ferreira R. An integrated perspective and functional impact of the mitochondrial acetylome. Expert Review of Proteomics 2014;11(3):383-94.

78. Gianazza E, Eberini I, Sensi C, Barile M, Vergani L, Vanoni MA. Energy matters: Mitochondrial proteomics for biomedicine. Proteomics 2011;11(4):657-74.

79. Gregersen N, Hansen J, Palmfeldt J. Mitochondrial proteomics--a tool for the study of metabolic disorders. Journal of inherited metabolic disease 2012;35(4):715-26.

80. Lau E, Huang D, Cao Q, Dincer TU, Black CM, Lin AJ, Lee JM, Wang D, Liem DA, Lam MP, Ping P. Spatial and temporal dynamics of the cardiac mitochondrial proteome. Expert Review of Proteomics 2015;12(2):133-46.

81. Forbes JM, Coughlan MT, Cooper ME. Oxidative stress as a major culprit in kidney disease in diabetes. Diabetes 2008;57(6):1446-54.

82. Kashihara N, Haruna Y, Kondeti VK, Kanwar YS. Oxidative stress in diabetic nephropathy. Current Medicinal Chemistry 2010;17(34):425669.

83. Tilton RG, Haidacher SJ, LeJeune WS, Zhang XQ, Zhao YX, Kurosky A Brasier AR, Denner L. Diabetes-induced changes in the renal cortical proteome assessed with two-dimensional gel electrophoresis and mass spectrometry. Proteomics 2007;7(10):1729-42.

84. Bugger $\mathrm{H}$, Chen D, Riehle C, Soto J, Theobald HA, Hu XX, Ganesan B, Weimer BC, Abel ED. Tissue-specific remodeling of the mitochondrial proteome in type 1 diabetic akita mice. Diabetes 2009;58(9):1986-97.

85. Zhang D, Yang H, Kong X, Wang K, Mao X, Yan X, Wang Y, Liu S, Zhang X, Li J, Chen L, Wu J, Wei M, Yang J, Guan Y. Proteomics analysis reveals diabetic kidney as a ketogenic organ in type 2 diabetes. American journal of physiology. Endocrinology and metabolism 2011;300(2):E287-95

86. Kartha GK, Moshal KS, Sen U, Joshua IG, Tyagi N, Steed MM, Tyagi SC. Renal mitochondrial damage and protein modification in type-2 diabetes. Acta diabetologica 2008;45(2):75-81.

87. Gong $D$, Chen $X$, Middleditch $M$, Huang $L$, Vazhoor Amarsingh G, Reddy S, Lu J, Zhang S, Ruggiero K, Phillips AR, Cooper GJ. Quantitative proteomic profiling identifies new renal targets of copper(II)-selective chelation in the reversal of diabetic nephropathy in rats. Proteomics 2009;9(18):4309-20.

88. Lee H, Abe Y, Lee I, Shrivastav S, Crusan AP, Huttemann M, Hopfer U, Felder RA, Asico LD, Armando I, Jose PA, Kopp JB. Increased mitochondrial activity in renal proximal tubule cells from young spontaneously hypertensive rats. Kidney international 2014;85(3):561-9.

89. Mujkosova J, Ulicna O, Waczulikova I, Vlkovicova J, Vancova O, Ferko M, Polak S, Ziegelhoffer A. Mitochondrial function in heart and kidney of spontaneously hypertensive rats: influence of captopril treatment. Gen. Physiol. Biophys. 2010;29(2):203-7.

90. Cowley AW, Jr., Abe M, Mori T, O'Connor PM, Ohsaki Y, Zheleznova NN. Reactive oxygen species as important determinants of medullary flow, sodium excretion, and hypertension. American journal of physiology. Renal physiology 2015;308(3):F179-97.

91. de Cavanagh EM, Toblli JE, Ferder L, Piotrkowski B, Stella I, Inserra F. Renal mitochondrial dysfunction in spontaneously hypertensive rats is attenuated by losartan but not by amlodipine. American journal of physiology. Regulatory, integrative and comparative physiology 2006;290(6):R1616-25.

92. Eirin A, Ebrahimi B, Zhang X, Zhu XY, Woollard JR, He Q, Textor SC, Lerman A, Lerman LO. Mitochondrial protection restores renal function in swine atherosclerotic renovascular disease. Cardiovascular research 2014;103(4):461-72.

93. Yu M, Wang XX, Du YX, Chen HJ, Guo XG, Xia L, Chen JZ. Comparative analysis of renal protein expression in spontaneously hypertensive rat. Clinical and Experimental Hypertension 2008;30(5):315-25.

94. Zheleznova NN, Yang C, Ryan RP, Halligan BD, Liang M, Greene AS, Cowley AW, Jr. Mitochondrial proteomic analysis reveals deficiencies in oxygen utilization in medullary thick ascending limb of Henle in the Dahl salt-sensitive rat. Physiological genomics 2012;44(17):82942.

95. Curthoys NP, Taylor L, Hoffert JD, Knepper MA. Proteomic analysis of the adaptive response of rat renal proximal tubules to metabolic acidosis. American journal of physiology. Renal physiology 2007;292(1):F140-7. 
96. Morigi M, Perico L, Rota C, Longaretti L, Conti S, Rottoli D, Novelli R, Remuzzi G, Benigni A. Sirtuin 3-dependent mitochondrial dynamic improvements protect against acute kidney injury. J Clin Invest 2015;125(2):715-26.

97. Ishimoto Y, Inagi R. Mitochondria: a therapeutic target in acute kidney injury. Nephrology Dialysis Transplantation 2015;Sep 1. [Epub ahead of print] doi:10.1093/ndt/gfv317

98. Charlwood J, Skehel JM, King N, Camilleri P, Lord P, Bugelski P, Atif $U$. Proteomic analysis of rat kidney cortex following treatment with gentamicin. Journal of proteome research 2002;1(1):73-82.

99. Klawitter J, Schmitz V, Brunner N, Crunk A, Corby K, Bendrick-Peart J, Leibfritz D, Edelstein CL, Thurman JM, Christians U. Low-salt diet and cyclosporine nephrotoxicity: changes in kidney cell metabolism. Journal of proteome research 2012;11(11):5135-44.

100. Veena CK, Josephine A, Preetha SP, Rajesh NG, Varalakshmi P. Mitochondrial dysfunction in an animal model of hyperoxaluria: a prophylactic approach with fucoidan. European journal of pharmacology 2008;579(1-3):330-6.

101. Thongboonkerd V, Semangoen T, Sinchaikul S, Chen ST. Proteomic analysis of calcium oxalate monohydrate crystal-induced cytotoxicity in distal renal tubular cells. Journal of proteome research 2008;7(11):4689-4700.

102. Semangoen T, Sinchaikul S, Chen ST, Thongboonkerd V. Altered proteins in MDCK renal tubular cells in response to calcium oxalate dihydrate crystal adhesion: a proteomics approach. Journal of proteome research 2008;7(7):2889-96.
103. Ahn CS, Metallo CM. Mitochondria as biosynthetic factories for cancer proliferation. Cancer Metabolism 2015;3(1):1-9.

104. Unwin RD, Craven RA, Harnden P, Hanrahan S, Totty N, Knowles M, Eardley I, Selby PJ, Banks RE. Proteomic changes in renal cancer and co-ordinate demonstration of both the glycolytic and mitochondrial aspects of the Warburg effect. Proteomics 2003;3(8):1620-32.

105. Yusenko MV, Ruppert T, Kovacs G. Analysis of differentially expressed mitochondrial proteins in chromophobe renal cell carcinomas and renal oncocytomas by 2-D gel electrophoresis. International journal of biological sciences 2010;6(3):213-24

106. Simonnet H, Alazard N, Pfeiffer K, Gallou C, Beroud C, Demont J, Bouvier R, Schagger $\mathrm{H}$, Godinot $\mathrm{C}$. Low mitochondrial respiratory chain content correlates with tumor aggressiveness in renal cell carcinoma. Carcinogenesis 2002;23(5):759-68.

107. Junker $\mathrm{H}$, Venz S, Zimmermann U, Thiele A, Scharf C, Walther R. Stage-related alterations in renal cell carcinoma-comprehensive quantitative analysis by 2D-DIGE and protein network analysis. PloS one 2011;6(7):e21867.

108. Vasko R, Mueller GA, von Jaschke AK, Asif AR, Dihazi H. Impact of cisplatin administration on protein expression levels in renal cell carcinoma: a proteomic analysis. European journal of pharmacology 2011;670(1):50-7.

109. Ozkok A, Edelstein CL. Pathophysiology of cisplatin-induced acute kidney injury. BioMed research international 2014;2014:967826. 